\title{
PERAN CSR PHE WMO DALAM MENURUNKAN EMISI GAS KENDARAAN BERMOTOR AKIBAT AKTIVITAS TRANSPORTASI PENGAMBILAN AIR KE SUNGAI Studi Kasus: Program HIPPAM Sumber Barokah Di Desa Bandangdaja, Kab. Bangkalan
}

\author{
Ika Bayu Kartikasari ${ }^{1}$, Helen Puspita Sari² \\ ${ }^{1}$ Universitas Gadjah Mada \\ Yogyakarta \\ ${ }^{2}$ CDO Pertamina Hulu Energy-West Madura Offshore \\ Gresik
}

\begin{abstract}
ABSTRAK
Desa Bandangdaja berada di perbukitan tanah kapur dan dengan tekstur tanah liat yang memiliki sedikit kandungan air. Masyarakat Desa Bandangdaja yang memperoleh air bersih yang terletak jauh dari pemukiman, kegiatan seperti mandi dan mencuci adalah disungai Lekgung yang terletak sekitar $3 \mathrm{Km}$ dari pemukiman. Masalah dihadapi masyarakat banyak menggunakan kendaraan bermotor untuk memperoleh sumber air dengan membawa keranjang dan ember untuk dibawa kerumah masing-masing sehingga menghasilkan sumber pencemaran yaitu emisi dari kendaraan bermotor. Pembakaran kendaraan bermotor pada umumnya memiliki dampak negatif terhadap lingkungan. PT. Pertamina PHE-WMO menginisiasi Program CSR dari dijalankan di Desa Bandangdaja, Kecamatan Tanjungbumi, Kabupaten Bangkalan yang berada di luar wilayah operasi Perusahaan atau Wilayah Ring II. dengan adanya program Air Bersih Berkelanjutan HIPPAM (Himpunan Penduduk Pemakai Air Minum) 'Sumber Barokah' memberikan bantuan HIPPAM Hidran dan melakukan pendampingan terkait pengelolaan program dengan mendorong kelompok membentuk Koperasi terbukti dapat mengurangi potensi emisi dari kendaraan bermotor dengan adanya inovasi air bersih yang dapat menghemat waktu masyarakat yang digunakan untuk mengambil air bersih dari sumber. Dari hasil penelitian didapatkan beban Emisi Kendaran pada polutan CO 4,35 ton/tahun. $\mathrm{HC}$ 6,72 ton/tahun, $\mathrm{NO}_{x}$ 0,33 ton/tahun, $\mathrm{SO}_{2}$ 0,009 ton/tahun, dan 3625,2 ton/tahun. Sedangkan peranan CSR secara umum pada pada sektor Ekonomi Desa Bandangdaja dapat terbantu dan menggerakkan perekonomian masyarakat dengan adanya Koperasi HIPPAM Sumber Barokah. Secara sosial Program ini telah menyediakan air bersih untuk tiga desa yang ada di Kecamatan Tanjung Bumi. Secara Kesejahteraan proses keberdayaan anggota kelompak HIPPAM Sumber Barokah dalam program CSR PHE WMO dapat menumbuhkan kapasitas sosial ekonomi kelompok serta meningkatkan taraf hidupnya secara mandiri.
\end{abstract}

Kata kunci: Emisi, CSR, Kendaraan bermotor

\begin{abstract}
Bandangdaja Village is located on hills of limestone soil and with a clay texture that has little water content, as a result, there are not many types of crops / agriculture that are quite reliable. People of Bandangdaja Village who get clean water which is located far from the settlement in the Lekgung River which is located about $3 \mathrm{Km}$ from the settlement. The problem is many people use motorized vehicles to obtain water sources by bringing baskets and buckets to their homes, resulting in a source of pollution. Motor vehicles in general has a negative impact on the environment. PT. Pertamina PHE-WMO initiated the CSR Program from being carried out in Bandangdaja Village, Tanjungbumi District, Bangkalan Regency which is outside the Company's operational area or Ring II Area.
\end{abstract}


with the Sustainable Clean Water program HIPPAM (Association of Drinking Water Users) 'Sumber Barokah' provides assistance to HIPPAM Hidran, and provides assistance related to program management by encouraging groups to form the Sumber Barokah HIPPAM Cooperative, proven to reduce potential emissions from motorized vehicles with clean water innovations which can save people the time used to extract clean water from sources. From the research results, it is found that the load of vehicle emissions on CO pollutants is 4.35 tons / year. HC 6.72 tonnes / year, NOx 0.33 tonnes / year, SO2 0.009 tonnes / year, and 3625.2 tonnes / year. Meanwhile, the role of CSR in general in the economic sector of Bandangdaja Village can be helped and stimulate the community's economy with the existence of the Sumber Barokah HIPPAM Cooperative. Socially, this program has provided clean water for three villages in Tanjung Bumi District. In terms of welfare, the empowerment process of the HIPPAM Sumber Barokah group members in the CSR PHE WMO program can foster the group's socio-economic capacity and improve its standard of living independently.

Keywords: Emission, CSR, motor vehicle

\section{PENDAHULUAN}

Air merupakan bagian paling penting yang membuat kehidupan di bumi. Semua organisme yang hidup tersusun dari sel-sel yang berisi air sedikitnya $60 \%$ dan aktivitas metabolik mengambil tempat di larutan air [1]. Kontur geografis wilayah Desa Bandangdaja berpengaruh terhadap tatanan sosiologis masyarakat. Wilayah Desa Bandangdaja didominasi oleh perbukitan tanah kapur dan dengan tekstur tanah liat yang memiliki sedikit kandungan air, akibatnya, tidak banyak jenis palawija/pertanian yang cukup bisa diandalkan [2].

Kebutuhan air warga mengandalkan sungai yang ada di desa untuk segala macam kebutuhan di musim kemarau, Khususnya untuk masyarakat Desa Bandangdaja yang memperoleh air bersih yang terletak jauh dari pemukiman, kegiatan seperti mandi dan mencuci adalah disungai Lekgung yang terletak sekitar $3 \mathrm{Km}$ dari pemukiman.

Masalah yang timbul yaitu masyarakat banyak menggunakan kendaraan bermotor untuk memperoleh sumber air dengan membawa keranjang dan ember untuk dibawa kerumah masing-masing sehingga menghasilkan sumber pencemaran yaitu emisi dari kendaraan bermotor. Pembakaran kendaraan bermotor pada umumnya memiliki dampak negatif terhadap lingkungan Karena hasil pembakaran kendaraan yang disebut dengan emisi gas dapat merusak lingkungan baik itu tanaman, air dan hewan maupun kehidupan manusia sendiri dengan timbulnya berbagai macam penyakit.

PT. Pertamina PHE-WMO menginisiasi Program Corporate Social Rssponsibility (CSR) yang dijalankan di Desa Bandangdaja, Kecamatan Tanjungbumi, Kabupaten Bangkalan yang berada di luar wilayah operasi Perusahaan atau Wilayah Ring II. dengan adanya program Air Bersih Berkelanjutan HIPPAM (Himpunan Penduduk Pemakai Air Minum) 'Sumber Barokah' dapat mengurangi potensi emisi dari kendaraan bermotor dengan adanya inovasi air bersih yang dapat menghemat waktu masyarakat yang digunakan untuk mengambil air bersih dari sumber. Keberhasilan Program CSR PHE WMO HIPPAM Sumber Barokah dapat dilihat melalui Input, proses, output, dan outcome yang didapatkan melalui monitoring dan Evaluasi Program.

PHE WMO berperan membentuk kelompok pengelola HIPPAM, kelompok diberikan peningkatan kapasitas untuk memanajemen program dan memberikan fasilitas pendukung HIPPAM dengan mengebor sumur, memberikan mesin HIPPAM Hidran, memasang tangki penampung air, dan pipa untuk penyaluran air kerumahrumah warga, peran PHE WMO tidak hanya sekedar charity, tapi juga melakukan pendampingan terkait pengelolaan program dengan mendorong kelompok membentuk Koperasi HIPPAM Sumber Barokah pada tahun 2016. 
CSR merupakan tanggung jawab sebuah organisasi terhadap dampak keputusan dan kegiatannya pada masyarakat dan lingkungan. Tanggung jawab sosial perusahaan tidak hanya terkait dengan ide pembangunan berkelanjutan. la juga terkait dengan harapan pemangku kepentingan (stakeholder) dimana aktivitas perusahaan berkaitan dengan kelompok-kelompok yang memiliki kepentingan atas operasinya [3].

Sehingga pada tujuan dari penelitian ini adalah (1) menganalisis jumlah emisi setelah adanya program CSR HIPPAM Sumber Barokah. (2) Analisis sosial ekonomi masyarakat melalui kegiatan CSR PHE WMO Air Bersih Berkelanjutan HIPPAM Sumber Barokah. (3) Analisis Perhitungan Nilai Kerugian Akibat Beban Emisi Kendaraan

\section{METODE PENELITIAN}

\subsection{Lokasi Penelitian}

Penelitian ini dilakukan di Desa Bandang Daya, Kabupaten Bangkalan. Desa Bandang Daya.

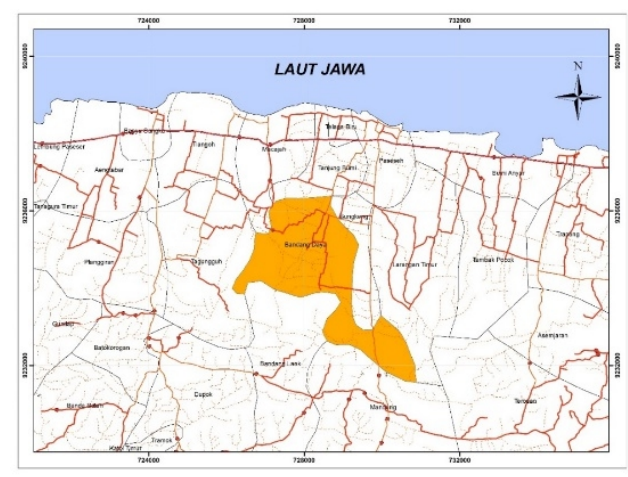

Gambar 2. Lokasi Penelitian

\subsection{Waktu dan Tempat}

Waktu dan Pelaksanaan penelitian ini dimulai pada tanggal 05 Januari 2020 sampai dengan 20 Februari 2020, yang berlokasi di Desa Bandangdaja Kecamatan Tanjungbumi Kab,Bangkalan Madura.

\subsection{Analisis Sosial Ekonomi \\ Untuk menganalisis}

sosial ekonomi menggunakan jenis penelitian deskriptif (descriptive Research) dengan pendekatan kualitatif. Dilakukan observasi dan wawancara yang digunakan dalam teknik pengumpulan data [4]. Selama penenilaian dilakukan dokumentasi untuk mengumpulkan data sekunder.

\section{Beban Emisi}

Tingkat aktivitas dinyatakan sebagai panjang perjalanan seluruh kendaraan bermotor. Sehingga formula perhitungan beban emisi dari kendaraan bermotor adalah:

$\mathrm{E}=$ Volume Kendaraan $\mathrm{x}$ VKT $\times \mathrm{FE} \times 10^{-6}$ (1)

Dimana:

E: Beban emisi (ton/tahun)

Volume Kendaraan: Jumlah kendaraan (kendaraan/tahun)

VKT: Total panjang perjalanan yang dilewati $(\mathrm{km})$

Fe: Faktor emisi (g/km/kendaraan)

\section{HASIL PENELITIAN}

\subsection{Hasil Perhitungan Emisi} Masyarakat Bandangdaja sebelum terdapat program HIPPAM, mengambil air dengan jarak $3 \mathrm{~km}$ dengan jalan kaki atau menggunakan kendaraan sepeda motor. Dari 400 pengguna HIPPAM di Desa Bandangdajah terdapat 200 pengguna yang menggunakan kendaraan sepeda motor. Jika emisi yang dihasilkan dari satu sepeda motor adalah seperti diatas, maka emisi yang dihasilkan oleh masyarakat Bandangdajah dalam sekali pengambilan air untuk 200 pengguna adalah sebagai berikut:

Tabel 1. Data Parameter Emisi Gas Desa Bandangdajah

\begin{tabular}{|c|c|c|c|c|c|c|c|}
\hline $\begin{array}{l}\text { Sat } \\
\text { uan } \\
\text { (mo } \\
\text { tor) }\end{array}$ & $\begin{array}{c}\mathrm{Ja} \\
\text { ra } \\
\mathrm{K} \\
\text { (K } \\
\mathrm{m})\end{array}$ & $\begin{array}{c}\mathrm{CO} \\
\text { (g/ } \\
\text { km } \\
\text { ) }\end{array}$ & $\begin{array}{c}\text { HC } \\
\text { (g/ } \\
\text { km } \\
\text { ) }\end{array}$ & $\begin{array}{c}\text { NO } \\
x \\
(g / \\
\text { km } \\
)\end{array}$ & $\begin{array}{c}\mathrm{C} \\
\mathrm{O}_{2} \\
(\mathrm{~g} / \\
\mathrm{kg} \\
\mathrm{B} \\
\mathrm{B} \\
\mathrm{M})\end{array}$ & $\begin{array}{c}\mathrm{CO}_{2} \\
(\mathrm{~g} / \mathrm{k} \\
\mathrm{g} \\
\mathrm{BB} \\
\mathrm{M})\end{array}$ & $\begin{array}{c}\text { SO } \\
2 \\
(\mathrm{~g} / \\
\mathrm{km} \\
\text { ) }\end{array}$ \\
\hline 200 & 6 & 16 & 70 & 38 & 28 & 381 & 9.6 \\
\hline /har & & 80 & 80 & 4 & 8 & 600 & \\
\hline i & & 0 & & & & 0 & \\
\hline
\end{tabular}

\subsection{Volume Lalu Lintas}

Survei dilakukan untuk mengetahui banyaknya jumlah kendaraan yang melintasi menuju sumber air sepanjang $6 \mathrm{~km}$ pada harihari biasa. Menurut penelitian Muziansyah, untuk memperoleh hasil volume lalu lintas selama 5 jam pada hari Senin dan Kamis [5]. Hasil survei 
volume lalu lintas dilakukan untuk memprediksi volume lalu lintas dalam 1 hari, 1 minggu dan 1 tahun dengan cara:

1 hari $=1$ jam $\times 12$ Lihat pada Tabel 2 .

1 Minggu $=(3 \times$ volume kendaraan hari Senin $)+(2 \times$ volume kendaraan hari Kamis).

1 Tahun $=52$ Minggu (hasil volume kendaraan 1 minggu dikalikan 52 minggu).

Tabel 2. Data Volume Lalu Lintas Kendaraan

\begin{tabular}{cccc}
\hline \multirow{4}{*}{ Kendaraan } \\
\cline { 2 - 4 } Hari & $\begin{array}{c}\text { Jumlah Kendaraan bermotor } \\
\text { (Kend/ }\end{array}$ & $\begin{array}{c}\text { (Kend/ } \\
\text { Minggu) }\end{array}$ & $\begin{array}{c}\text { (Kend/ } \\
\text { Tahun) }\end{array}$ \\
\hline Senin & 200 & 996 & 51792 \\
Kamis & 198 & & \\
\hline
\end{tabular}

\section{PEMBAHASAN}

\subsection{Analisis Ekonomi Masyarakat}

Dari segi Ekonomi pada program CSR PHE WMO Air Bersih Berkelanjutan HIPPAM Sumber Barokah, dimensi kompas Ekonomi dapat mencakup hal-hal seperti pekerjaan, upah, pasar, produksi dan konsumsi, energi, penelitian dan pengembangan, investasi, pendapatan, hutang, distribusi dan lain-lain. pada pendapatan yang dihasilkan oleh HIPPAM Sumber Barokah diperoleh dari setiap KK yang menjadi anggota dikenakan biaya Rp.5.000 per meter kubik air.

Pada setiap bulannya warga akan membayar air yang sudah dipergunakan. setelah diakumulasikan penghasilan HIPPAM dari tahun 2018-2020 sebesar Rp.237.715.000. salah satu keunikan Koperasi HIPPAM Sumber Barokah adalah sistem pembayaran dilakukan tidak hanya menggunakan uang tunai, tapi juga dengan bentuk non tunai berupa hasil pertanian warga. Sistem pembayaran ini sangat membantu masyarakat yang memiliki kesulitan ekonomi dan hanya bekerja sebagai petani ketika musim hujan, jika tidak musim hujan masyarakat berhutang sampai panen atau anak yang bekerja yang diperantauan yang membayarkan.

Penghasilan tersebut digunakan oleh Koperasi HIPPAM Sumber Barokah untuk kegiatan simpan, pinjam, deposit dan investasi, sistem pinjam tidak menggunakan jaminan namun bersifat kepercayaan antar masyarakat dengan koperasi saja seperti peminjaman dilakukan oleh masyaraakat sebesar Rp.1.000.000 akan diangsur per minggu sebesar Rp.25.000, selama 1 tahun ada 50 Minggu, sehingga pinjaman terbayar sebesar RP.1.250.000 dan Rp.250.000 operasional yang diberikan kepada koperasi.

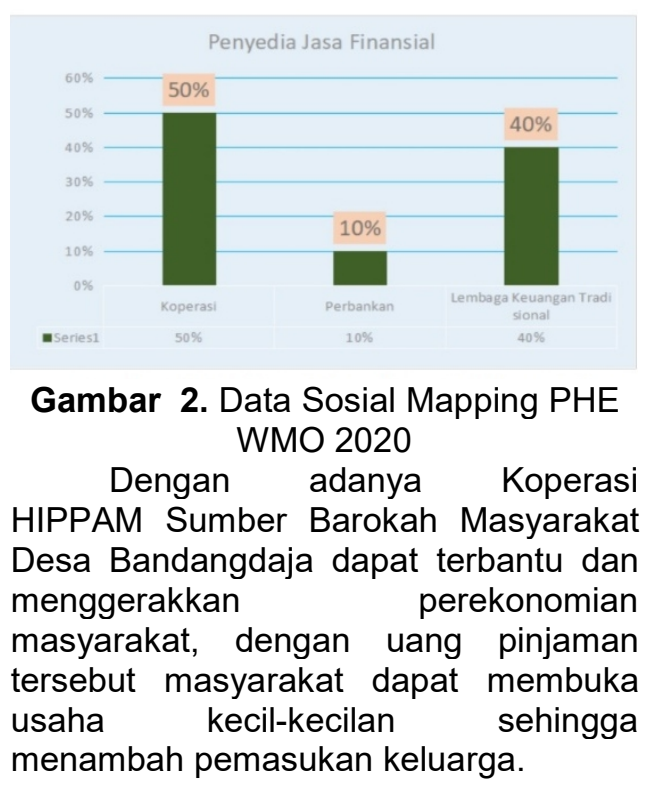

\subsection{Analisis Sosial Masyarakat}

Dari segi Masyarakat pada program CSR PHE WMO Air Bersih Berkelanjutan HIPPAM Sumber Barokah, berfokus pada pemberdayaan masyarakat yang dilakukan melalui pendampingan pengelolaan program HIPPAM, Kelompok yang sudah ada kemudian didorong membentuk Koperasi HIPPAM Sumber Barokah.

Sampai saat ini, Koperasi HIPPAM Sumber Barokah telah menyediakan air bersih untuk tiga desa yang ada di Kecamatan Tanjung Bumi, yaitu Desa Bandangdaja, Desa Tanjung Bumi dan Desa Tlaga Biru. tercatat 400 kepala Keluarga yang menikmati air bersih melalui koperasi HIPPAM ini dan 20 KK dari kelompok rentan memperoleh akses air bersih melalui iuran non tunai dengan membayar menggunakan hasil pertanian di Desa Bandangdaja. 


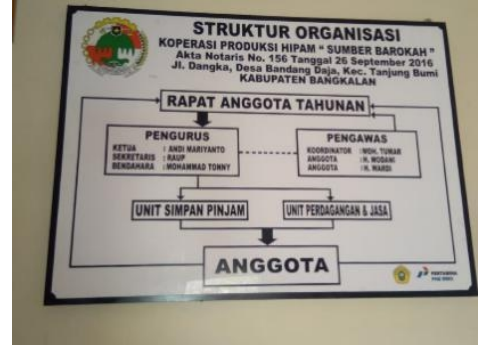

Gambar 3. Data Sekunder

\subsection{Kesejahteraan Masyarakat}

Kesejahteraan mengacu pada kepuasan dan kebahagiaan orangorang, kesehatan fisik dan sosio emosional, kesehatan mereka secara keseluruhan, tingkat kepuasan hidup pribadi, tabungan utama, dan peluang untuk mengembangkan potensi.

Masyarakat Desa Bandangdaja sudah sejahtera untuk memenuhi kebutuhan keluarga terhadap air, penyakit kulit akibat air juga sudah menurun sebanyak 50\%, dan Masyarakat telah memperoleh perubahan mindset untuk mengembangkan potensi yang ada di Desa Bandangdaja. seperti adanya usaha-usaha baru seperti mencelup batik, mengelola hasil pertanian menjadi produk yang bernilai jual dan mengelola air minum isi ulang.

Pemberdayaan menurut (Jame Ife dalam Syafar,2012) "empowerment is a process of helping disadvantaged groups and individual to compete more effectively with other interest, by helping them to learn and use in lobbying, using the media, engaging in political action, understanding how to work the system and so on". Pemberdayaan dimaknai sebagai sebuah intervensi yang merupakan suatu upaya memperkuat sumberdaya dan partisipasi masyarakat agar meningkatkan kapasitasnya agar dapat menentukan masa depannya sendiri.

\section{Berdasarkan}

konsep pemberdayaan diatas, maka pemberdayaan dibatasi pada upaya proses keberdayaan anggota kelompak HIPPAM Sumber Barokah dalam program CSR PHE WMO untuk menumbuhkan kapasitas sosial ekonomi kelompok serta meningkatkan taraf hidupnya secara mandiri. Upaya yang dilakukan dengan memperkuat potensi atau daya yang dimiliki oleh masyarakat itu sendiri. Sehingga dalam memahami pemberdayaan sebagai aktivitas yang meletakkan proses yang tidak menafikan hasil, sebagai basis pelaksanaan program, serta tidak bisa dipisahkan dari peran pendampingan kepada kelompok sasaran.

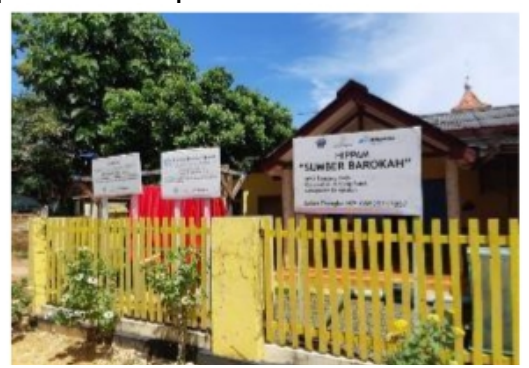

Gambar 4. kantor Sekretariat Koperasi HIPPAM Sumber Barokah

\subsection{Analisis Beban Emisi Kendaraan}

Dengan Faktor Emisi Indonesia Pada penelitian ini analisis perhitungan beban emisi kendaraan menggunakan metode perhitungan beban emisi berdasarkan Peraturan Menteri Negara Lingkungan Hidup No. 12 Tahun 2010.

Tabel 3. Data Faktor Emisi Indonesia.

\begin{tabular}{|c|c|c|c|c|c|c|}
\hline $\begin{array}{l}\text { Kateg } \\
\text { ori } \\
\text { Kenda } \\
\text { raan }\end{array}$ & $\begin{array}{l}\mathrm{CO} \\
(\mathrm{g} / \mathrm{k} \\
\mathrm{m})\end{array}$ & $\begin{array}{l}\mathrm{HC} \\
(\mathrm{g} / \mathrm{k} \\
\mathrm{m})\end{array}$ & $\begin{array}{l}\text { NO } \\
x \\
(g / k \\
m)\end{array}$ & $\begin{array}{l}\mathrm{CO} \\
2 \\
\text { (g/ } \\
\mathrm{kg} \\
\mathrm{BB} \\
\mathrm{M})\end{array}$ & $\begin{array}{l}\text { CO } \\
2 \\
\text { (g/ } \\
\mathrm{kg} \\
\mathrm{BB} \\
\mathrm{M})\end{array}$ & $\begin{array}{l}\text { SO } \\
2 \\
(g / k \\
m)\end{array}$ \\
\hline $\begin{array}{l}\text { Seped } \\
\text { a } \\
\text { Motor }\end{array}$ & 14 & 5,9 & $\begin{array}{l}0,2 \\
9\end{array}$ & $\begin{array}{l}0,2 \\
4\end{array}$ & $\begin{array}{l}31 \\
80\end{array}$ & $\begin{array}{l}0,0 \\
08\end{array}$ \\
\hline $\begin{array}{l}\text { Mobil } \\
\text { Pribad } \\
\text { i }\end{array}$ & 40 & 4 & 2 & $\begin{array}{l}0,0 \\
1\end{array}$ & $\begin{array}{l}31 \\
80\end{array}$ & $\begin{array}{l}0,0 \\
26\end{array}$ \\
\hline $\begin{array}{l}\text { Mobil } \\
\text { Solar }\end{array}$ & 2,8 & 0,2 & 3,5 & $\begin{array}{l}0,5 \\
3\end{array}$ & $\begin{array}{l}31 \\
72\end{array}$ & $\begin{array}{l}0,4 \\
4\end{array}$ \\
\hline
\end{tabular}

Setelah didapat data volume kendaraan per tahun, data panjang perjalanan serta faktor emisi berdasarkan kategori kendaraan dilakukan perhitungan beban emisi kendaraan. Contoh perhitungan beban emisi untuk polutan jenis $\mathrm{CO}$ dapat dilihat dibawah ini:

CO kendaraan berbahan bakar solar (ton/tahun):

$=$ Volume Kendaraan $\times$ VKT $\times$ FE $\times 10^{-6}$

$=51792 \mathrm{kend} / \mathrm{tahun} \times 6 \mathrm{~km} \times 14 \mathrm{~g} / \mathrm{km} \times$ $10^{-6}$

$=4,35$ ton/tahun 
Cara perhitungan beban emisi kendaraan untuk jenis polutan $\mathrm{HC}, \mathrm{NOx}$, $\mathrm{CO}_{2}$, dan $\mathrm{SO}_{2}$ hampir sama dengan cara perhitungan beban emisi untuk jenis polutan $\mathrm{CO}$, hanya saja pada faktor emisi (FE) bahan pencemar menggunakan jumlah kendaraan perjam. Sedangkan cara perhitungan yang berbeda berlaku untuk jenis polutan $\mathrm{CO}_{2}$ karena berkaitan dengan konsumsi bahan bakar kendaraan.

Data yang diperlukan antara lain:

1. Data konsumsi rata - rata bahan bakar kendaraan.

Konsumsi bahan bakar sepeda motor rata - rata dalam kota sebesar $48 \mathrm{~km} / \mathrm{liter}$.

2. Berat jenis solar sebesar 0,82 $\mathrm{kg} / \mathrm{liter}$ dan berat jenis premium sebesar $0,76 \mathrm{~kg} / \mathrm{liter}$.

3. Panjang perjalanan di ke lokasi sumber air pulang-pergi yaitu $6 \mathrm{~km}$.

Perhitungan $\mathrm{CO}_{2}$ kendaraan bermotor:

$$
\begin{aligned}
& 48 / 6=1 / x \\
& 4 \mathrm{x}=6 \\
& x \quad=1,5 \text { liter } \\
& =1,5 \text { liter } \times 0,76 \mathrm{~kg} / \mathrm{liter} \\
& =1,14 \mathrm{~kg}
\end{aligned}
$$

$\mathrm{FE} \mathrm{CO} 2$ sepeda motor $=3180 \mathrm{~g} / \mathrm{kg} \mathrm{BBM}$ Bila faktor emisi untuk $1 \mathrm{~kg}$ BBM solar sebesar 3180 gram, maka untuk 0,0035 kg BBM solar sebesar:

$$
\begin{aligned}
& 1 / 1,14=3180 / x \\
& \mathrm{x} \quad=3180 \times 1,14 \\
& x \quad=3625,2 \text { gram }
\end{aligned}
$$

Berdasarkan contoh perhitungan diatas diperoleh hasil perhitungan beban emisi seperti di bawah ini:

Tabel 4. Beban Emisi Kendaraan Sepeda Motor Per Tahun (ton/tahun)

\begin{tabular}{cccccc}
\hline & \multicolumn{5}{c}{ Kendaraan Sepeda Motor } \\
\cline { 2 - 6 } Ruas & $\mathrm{C}$ & $\mathrm{HC}$ & $\mathrm{NO}_{\mathrm{x}}$ & $\mathrm{SO}_{2}$ & $\mathrm{CO}_{2}$ \\
\hline Sepanj & $\mathrm{O}$ & & & & \\
ang & & & & & \\
jalan & 4,3 & 6,7 & 0,33 & 0,009 & 3625 \\
menuju & 5 & 26 & 06 & 12 &, 2 \\
$\begin{array}{c}\text { Sumber } \\
\text { air }\end{array}$ & & & & & \\
\hline
\end{tabular}

\subsection{Analisis Perhitungan Nilai Kerugian Akibat Beban Emisi Kendaraan}

Biaya kerugian emisi kendaraan merupakan nilai beban emisi kendaraan yang Perhitungan analisis beban emisi yang diperoleh dari meningkatnya volume kendaran yang menyebabkan kemacetan, maka penelitian ini ingin melihat dampak negatif yaitu kerugian dalam segi ekonomi dengan memperkirakan biaya perton emisi dari masing masing polutan yang dihasilkan dari kendaraan menggunakan asumsi biaya berdasarkan biaya polutan yang dipakai pada penelitian Victoria Transport Policy Institute [6]. Victoria Transport Policy Institute (VTPI) adalah organisasi riset independen yang didedikasikan untuk mengembangkan solusi inofatif dan praktis dalam masalah transportasi mengenai tingkat polusi udara kendaraan bermotor. Berikut beberapa biaya polutan dari riset yang dilakukan di Kanada tahun 2005 (\$/ton):

1. Karbon Monoksida (CO) $=\$ 205 /$ ton

2. Partikulat $\left(\mathrm{PM}_{10}\right)=\$ 3,17 /$ ton

3. Karbon Dioksida $\left(\mathrm{CO}_{2}\right)=\$ 205 /$ ton

4. Sulfur Dioksida $\left(\mathrm{SO}_{2}\right)=\$ 1000 /$ ton

5. Nitrogen Oksida $\left(\mathrm{No}_{\mathrm{x}}\right)=\$ 934 /$ ton

6. Hidrokarbon $=\$ 44 /$ ton

Dalam penelitian ini biaya emisi \$ dollar/ton diubah kedalam mata uang Indonesia (Rupiah), dimana $1 \$$ dollar = Rp. 14.025. Kurs nilai mata uang dilihat pada bulan Februari 2020. Berikut biaya polutan (Rupiah/ton):

1. Karbon Monoksida $(\mathrm{CO})=\mathrm{Rp}$. 2.875.125/ton

2. Nitrogen Oksida $\left(\mathrm{No}_{x}\right)=\mathrm{Rp}$. 13.099.350/ton

4. Hidrokarbon $617.100 /$ ton

5. Sulfur Dioksida $\left(\mathrm{SO}_{2}\right)=\mathrm{Rp}$. 14.025.000/ton

6. Karbon Dioksida $\left(\mathrm{CO}_{2}\right)=\mathrm{Rp}$. 2.875.125/ton

Berdasarkan nilai kerugian di atas dapat dihitung besaran kerugian akibat beban emisi di Desa Bandangdaja pada Tabel 5 di bawah ini:

Tabel 5. Analisis Biaya Kerugian Emisi

\begin{tabular}{cclr}
\hline \multirow{2}{*}{ Polutan } & \multicolumn{2}{c}{ Kendaraan Sepeda Motor } \\
\cline { 2 - 5 } & $\begin{array}{c}\text { Beban } \\
\text { Emisi }\end{array}$ & \multicolumn{2}{c}{ Total Kerugian } \\
\hline $\mathrm{CO}$ & 4,35 & $\mathrm{Rp}$ & $12.506 .793,75$ \\
$\mathrm{HC}$ & 6,726 & $\mathrm{Rp}$ & $4.150 .614,60$ \\
$\mathrm{NO}_{x}$ & 0,3306 & $\mathrm{Rp}$ & $4.330 .645,11$ \\
$\mathrm{SO}_{2}$ & 0,00912 & $\mathrm{Rp}$ & $127.908,00$ \\
$\mathrm{CO}_{2}$ & 3625,2 & $\mathrm{Rp} 10.422 .903 .150,00$ \\
\hline
\end{tabular}




\section{KESIMPULAN}

Bedasarkan hasil analisis data yang dilakukan dalam penelitian ini, kesimpulan yang dapat diperoleh adalah sebagai berikut.

1. Program CSR PHE WMO telah memberikan dampak pada perbaikan lingkungan dan sosial, dampak lingkungan dengan berkurangnya Beban Emisi Kendaran pada polutan $\mathrm{CO} 4,35$ ton/tahun. $\mathrm{HC} 6,72$ ton/tahun, $\mathrm{NO}_{\mathrm{x}}$ 0,33 ton/tahun, $\mathrm{SO}_{2} \quad 0,009$ ton/tahun, dan 3625,2 ton/tahun.

2. Secara sosial Program ini telah menyediakan air bersih untuk tiga desa yang ada di Kecamatan Tanjung Bumi. Secara Ekonomi Desa Bandangdaja dapat terbantu dan menggerakkan perekonomian masyarakat dengan adanya Koperasi HIPPAM Sumber Barokah. dan Secara Kesejahteraan proses keberdayaan anggota kelompak HIPPAM Sumber Barokah dalam program CSR PHE WMO dapat menumbuhkan kapasitas sosial ekonomi kelompok serta meningkatkan taraf hidupnya secara mandiri.

3. Nilai kerugian akibat emisi kendaraan merupakan nilai beban emisi kendaraan biaya polutan (Rupiah/ton) yang dihasilkan yaitu Karbon Monoksida (CO) Rp. 2.875.125/ton, Nitrogen Oksida $\left(\mathrm{No}_{\mathrm{x}}\right)=$ Rp. 13.099.350/ton, Hidrokarbon = Rp. 617.100/ton, Sulfur Dioksida $\left(\mathrm{SO}_{2}\right)=\mathrm{Rp}$. 14.025.000/ton, dan Karbon Dioksida $\left(\mathrm{CO}_{2}\right)=$ Rp. 2.875.125/ton.

\section{SARAN}

Saran dan rekomendasi yang dapat dihasilkan dari penelitian ini diantaranya sebagai berikut.

1. Program HIPPAM Sumber Barokah telah mampu memenuhi kebutuhan air rumah tangga dan mengurangi emisi kendaraan bermotor yang terjadi di Desa Bandangdaja, namun perlu adanya pengembangan program yang digunakan untuk meningkatkan produktivitas kegiatan masyarakat terutama untuk pertanian di Desa Bandangdaja program HIPPAM belum bisa memenuhi kebutuhan pengairan untuk pertanian sehingga masyarakat bertani pada saat musim hujan yang mengakibatkan banyaknya lahan kritis dan tidak dimanfaatkan.

2. Program-program Corporate Social Responsibility (CSR) perlu terus dievaluasi dan disesuaikan dengan kebutuhan masyarakat, pada penelitian selanjutnya dapat dilakukan penelitian dampak ekonomi masyarakat setelah adanya program HIPPAM Sumber Barokah. agar lebih terlihat keberhasilan program tersebut.

\section{UCAPAN TERIMA KASIH}

Jurnal ini ialah karya studi dan kolaborasi antara ilmu lingkungan dan CSR, perusahaan pada saat ini tidak hanya memikirkan Profit semata namun dituntut untuk melakukan tanggungjawab sosial perusahaan yang memberikan perbaikan berkelanjutan untuk lingkungan (Planet) dan Masyarakat secara luas (people). Penulis menghaturkan ucapan terimakasih kepada seluruh elemen yang berada dalam lingkaran penulis. dan apresiasi setinggi-tingginya. Terutama kepada Allah Swt sang pemilik alam semesta yang senantiasa melimpahkan rahmat kesehatan dan memelihara energi semangat penulis.

\section{DAFTAR PUSTAKA}

1. Enger, E.D. dan Smith, B.F. 2000. Environmental Science - A Study of Interrelationship. 7 ed. McGraw Hill.

2. SODEC. 2020: Laporan Sosial Mapping Desa Bandangdaja, Pembangunan Sosial dan Kesejahteraan:UGM.

3. Final Draft ISO 26000 "Guidance on Social Responsibility.

4. Sofyanty, Y. R, D. Hamid, dan R. Y. Dewantara. 2017. Analisis Penerapan CSR dan Dampak Terhadap Kehidupan Sosial Ekonomi Masyarakat (Studi Kasus Pada Hotel Ibis Surabaya City Center). Jurnal Administrasi Bisnis Vol 42 (2): 26-31.

5. Muziansyah, D, R. Sulistyorini, dan S. Sebayang. 2015. Model Emisi 
Gas Buangan Kendaraan Bermotor Akibat Aktivitas Transportasi (Studi Kasus: Terminal Pasar Bawah Ramayana Koita Bandar Lampung). JRSDD 3(1): 57-70.

6. Victoria Transport Policy Institute. 2011. Transportation Cost and Benefit Analysis II. Australia. 